\title{
Cholesterol-lowering Effect of Mevinolin, an Inhibitor of 3-Hydroxy-3-Methylglutaryl-Coenzyme A Reductase, in
}

\section{Healthy Volunteers}

\author{
J. A. Tobert, G. D. Bell, J. Birtwell, I. James, W. R. Kukovetz, J. S. Pryor, \\ A. BuntinX, I. B. Holmes, Y-S. ChaO, and J. A. Bolognese, Merck Sharp d \\ Dohme Research Laboratories, Rahway, New Jersey; Nottingham City \\ Hospital, Nottingham, England; Welsh National School of Medicine, Cardiff, \\ Wales; Royal Free Hospital, London, England; University of Graz, Austria; \\ Norfolk and Norwich Hospital, Norwich, England
}

\begin{abstract}
A B S T R A C T Mevinolin reduces cholesterol synthesis by inhibiting 3-hydroxy-3-methylglutaryl-coenzyme A reductase. The safety and effectiveness of this agent was evaluated in a double-blind, placebo-controlled study in 59 healthy men (serum cholesterol 3.88-7.76 $\mathrm{mmol} / \mathrm{liter}$ ) in five centers. Subjects maintained their usual diet and activities. Doses of $6.25,12.5,25$, or 50 $\mathrm{mg}$ twice daily for 4 wk produced mean reductions of total serum cholesterol of $23-27 \%$ [vs. placebo (4\%), $P<0.01]$. Mean low density lipoprotein cholesterol fell $35-45 \%$, while high density lipoprotein and very low density lipoprotein cholesterol, and triglycerides were not significantly affected. Mean apolipoprotein B fell $27-34 \%$. $50 \mathrm{mg}$ was not significantly more effective than $6.25 \mathrm{mg}$. Mevinolin was generally well tolerated, and no serious clinical or laboratory abnormalities occurred. One subject $(12.5 \mathrm{mg}$ ) was withdrawn because of abdominal pain and diarrhea. These results suggest that if long-term safety can be demonstrated, inhibitors of 3-hydroxy-3-methylglutaryl-coenzyme A reductase are likely to prove useful in the treatment of hypercholesterolemia.
\end{abstract}

\section{INTRODUCTION}

Elevated serum cholesterol is a major factor in the development of atherosclerosis and coronary heart disease $(1,2)$. There is a substantial and currently unsatisfied need for safe, well tolerated therapy capable of effecting large reductions in serum cholesterol. Mevinolin [MK-803, 1,2,6,7,8,8a-hexahydro- $\beta, \delta$-dihydroxy-2,6-dimethyl-8-(2-methyl-1-oxobutoxy)-1 -

Received for publication 21 September 1981 and in revised form 14 December 1981. naphthalene-heptanoic acid $\delta$-lactone], a fermentation product derived from Aspergillus terreus, is rapidly converted in vivo to the corresponding hydroxy acid, mevinolinic acid, which is a potent competitive inhibitor of 3-hydroxy-3-methylglutaryl-coenzyme A reductase (E.C. 1.1.1.34; HMG-CoA ${ }^{1}$ reductase) (3); this enzyme catalyzes the conversion of 3-hydroxy-3-methylglutaryl-coenzyme $A$ to mevalonate, which is the rate-limiting step in the cholesterol synthesis pathway (4). Mevinolin lowers serum cholesterol in dogs $(3,5)$, and in a pilot study in healthy men it was well tolerated and exerted a rapid and substantial cholesterol-lowering effect (6).

The purpose of this investigation was to estimate the safety, tolerability, and efficacy of mevinolin at various doses in healthy normocholesterolemic volunteers, and thereby to obtain data required for the design of subsequent studies in hypercholesterolemic patients. Efficacy was assessed by determination of cholesterol in high density lipoprotein (HDL), low density lipoprotein (LDL), and very low density lipoprotein (VLDL), and apolipoprotein B and triglycerides, over a 4-wk treatment period. Safety and tolerability were assessed by routine clinical and laboratory measurements. In addition, because cholesterol is the precursor of all steroid hormones, the possibility that mevinolin could reduce steroidogenesis was investigated by mea-

\footnotetext{
${ }^{1}$ Abbreviations used in this paper: CPK, creatine phosphokinase; HDL, high density lipoprotein; HMG-CoA, 3hydroxymethylglutaryl-coenzyme A; LDL, low density lipoprotein; SGOT, serum glutamic oxalo-acetic-acid transaminase; SGPT, serum glutamic pyruvic transaminase; VLDL, very low density lipoprotein.
} 
surement of plasma cortisol and testosterone, and urinary excretion of 17-hydroxysteroids and 17-ketosteroids.

\section{METHODS}

Subjects. 59 healthy male volunteers (mainly medical students, physicians, and laboratory technicians), mean age 28.6 , SD 6.2 , range 18 to 45 , participated in the study after giving informed consent. There were 12 subjects in Cardiff, Graz, Norwich, and Nottingham, and 11 in London. Before entering the study, all subjects underwent a prestudy screen consisting of a physical examination and routine hematology, serum chemistry, and urinalysis (see below). Potential subjects with serum cholesterol $<3.88$ or $>7.76 \mathrm{mmol} /$ liter were excluded; other exclusion criteria were current regular use of any drugs, a history of drug or alcohol abuse, and multiple and/or severe allergies.

Treatments. After a single-blind placebo run-in period of $2 \mathrm{wk}$ (days 1R-14R), each subject received on a doubleblind basis one of the following six treatments for $4 \mathbf{w k}$ (days 1-28): mevinolin $6.25,12.5,25,50 \mathrm{mg}$ bid, $25 \mathrm{mg}$ qd, or placebo. In order that the mean and distribution of the baseline serum cholesterol would be similar for all groups, subjects were ranked according to their serum cholesterol as measured during the prestudy screen, and the allocation to treatment was determined by rank; allocation was otherwise random. There were thus 10 subjects in each treatment group, except for $50 \mathrm{mg}$ bid, where there were 9 , and each center had 2 subjects in each of the 6 treatment groups, except for London, where there was only 1 subject in the 50-mg bid treatment group.

Micronized drug was formulated with cornstarch in capsules of identical appearance. Medication was taken before breakfast and dinner. In the case of the 25-mg qd regimen, active drug was taken in the morning and a placebo capsule was taken in the evening. Compliance was monitored by subject diaries.

The subjects maintained their usual diet and activities, except that alcohol intake was restricted to $200 \mathrm{ml}$ wine or $500 \mathrm{ml} \mathrm{beer} / \mathrm{d}$.
Sample collection. Fasting blood samples were collected immediately before the morning dose at $\sim 0900 \mathrm{~h}$ on day 1 of the run-in period (day $1 R$ ), $4 R, 8 R, 11 R, 15 R$ (=day 1 ), $4,8,11,15,24$, and 29 (days $15 \mathrm{R}$ and 29 are the days following the last placebo run-in day and active treatment day, respectively.) All samples were analyzed for total serum cholesterol, cholesterol in the VLDL, LDL, and HDL fractions, and triglycerides. Samples drawn on days $8 R, 11 R$, $15 R, 11,24$, and 29 were also analyzed for apolipoprotein B.

Routine hematology, liver function tests-serum glutamic oxalo-acetic-acid transaminase (SGOT) (four centers) and/ or serum glutamic pyruvic transaminase (SGPT) (three centers), alkaline phosphatase and total bilirubin-creatinine, fasting blood sugar, lactic dehydrogenase, creatine phosphokinase (CPK), albumin, and globulin (or albumin/globulin ratio) were measured in the prestudy screen and on days $8 R, 15 R, 4,8,15$, and 29 . In three centers, the liver function tests were also performed on day 22 .

Plasma cortisol and testosterone were measured in the samples collected on days $8 R$ and 29 . Routine urinalysis was performed on days $8 R, 15 R, 4,8,15$, and 29. 24-h urines were collected on days $8 R$ and 29 for 17 -hydroxysteroids and 17-ketosteroids.

Analytical methods. The laboratories in the five centers used their usual methods for total cholesterol, HDL cholesterol, triglycerides, plasma cortisol, plasma testosterone, 17hydroxysteroids, and 17-ketosteroids. These are given in Table I. HDL cholesterol was directly measured using precipitation methods, and VLDL and LDL cholesterol were estimated according to the approximation of Friedewald et al. (21): total cholesterol $=($ HDL + LDL + VLDL) cholesterol, where VLDL cholesterol concentration $=0.80$ triglycerides concentration (in SI units). The validity of this approximation under the conditions of this study was checked in two centers (Cardiff and London), which also measured VLDL directly, using double precipitation methods $(22,10)$. Serum for determination of apolipoprotein $B$ was frozen and shipped to Rahway, NJ, where the radial immunodiffusion method of Sniderman et al. (23) was used. Laboratory safety tests were performed using routine automated methods.

TABLE I

Analytical Methods

\begin{tabular}{|c|c|c|c|c|c|c|c|}
\hline Center & $\begin{array}{l}\text { Total serum } \\
\text { cholesterol }\end{array}$ & $\begin{array}{c}\text { HDL } \\
\text { cholesterol }\end{array}$ & Triglycerides & $\begin{array}{l}\text { Plasma } \\
\text { cortisol }\end{array}$ & $\begin{array}{c}\text { Plasma } \\
\text { testosterone }\end{array}$ & $\begin{array}{l}\text { Urinary } \\
\text { 17-hydroxy } \\
\text { steroids }\end{array}$ & $\begin{array}{l}\text { Urinary } \\
\text { 17-keto } \\
\text { steroids }\end{array}$ \\
\hline Cardiff & $7, \mathbf{A}$ & 10 & $12, \mathrm{D}$ & 15 & 17 & 19 & 20 \\
\hline Graz & $7, \mathbf{A}$ & $11, \mathrm{C}$ & $13, E$ & $\mathbf{F}$ & G & $\mathbf{J}$ & $\mathbf{J}$ \\
\hline London & 8 & 10 & 14 & $\mathbf{F}$ & $\mathbf{H}$ & 19 & 20 \\
\hline Norwich & $7, \mathrm{~A}$ & $11, \mathrm{C}$ & $13, E$ & 16 & I & 19 & 20 \\
\hline Nottingham & $9, \mathrm{~B}$ & 10 & $13, E$ & $\mathbf{F}$ & 18 & 19 & 20 \\
\hline
\end{tabular}

Numbers indicate references and letters indicate the following kits: A = Monotest cholesterol (CHOD - PAP method), Boehringer Mannheim GmbH, Mannheim, W. Germany. B = Total cholesterol reagent set (enzymatic), Macomb Chemical Co., Inc., Mt. Clemens, MI. C = Test combination HDL - cholesterol, Boehringer Mannheim GmbH. D = Coulter triglycerides enzymatic, Coulters Electronic Ltd., Luton, Bedfordshire, England. E = Triglyceride fully enzymatic UV-test, Boehringer Mannheim GmbH. F = Amerlex cortisol RIA kit, Amersham Radiochemical Centre, Amersham, Buckinghamshire, England. G = Testosterone/dihydrotestosterone RIA kit, Amersham Radiochemical Centre. H = Testosterone RIA kit, Serono Laboratories Ltd., Welwyn Garden City, Hertfordshire, England. I = Nordiclab testosterone RIA test, Nordiclab, Oulu, Finland. J = Ketochrome column test for 17-ketosteroids and 17-hydroxycorticosteroids, Bio-Rad Laboratories, Richmond, CA. 
Clinical measures. A complete physical examination was carried out before and after the study. Sitting pulse and blood pressure, temperature, and three lead electrocardiogram (ECG) were recorded on days $8 R, 4,15$, and 29 . Inquiry for adverse effects was made at each clinic visit.

Statistical analysis. For each blood and urine variable, within-group changes from base line were analyzed using a paired $t$ test. The base line was taken to be the average of the three values recorded during the week preceding the start of active treatment (i.e., days 8R, 11R, and 15R). Also, between-group analysis of variance (blocked by center and including the center-by-treatment interaction effect) was carried out. Of the 15 possible pairwise comparisons, 7 were of interest: placebo vs. the mevinolin groups, $6.25 \mathrm{mg}$ bid vs. $25 \mathrm{mg}$ qd, and $12.5 \mathrm{mg}$ bid vs. $25 \mathrm{mg}$ qd. These pairwise comparisons were made using Bonferroni's method as described by Dunn (24) after removing the effect of differences between centers (25).

In addition, the data from the mevinolin bid groups were assessed using a regression analysis. The regression analysis was performed using a log transformation (i.e., to obtain the values $1,2,3,4$ ) on the independent variable (dose of mevinolin). A significant regression coefficient can be interpreted as an indication of a dose-related response. For the measurements of total, HDL, and LDL cholesterol, triglycerides and apolipoprotein $B$, percent change from base line was also assessed.

\section{RESULTS}

57 of the 59 subjects completed the study. AN 38 (12.5 $\mathrm{mg}$ bid) was withdrawn on day 21 because of adverse effects (see below), and AN 41 (6.25 mg bid) withdrew for personal reasons on day 25 . Because of a dispensing error, AN 10 ( $50 \mathrm{mg}$ bid) received medication on days 21-28 intended for AN 12 (12.5 mg bid), and vice versa, and the day 29 values for these two subjects were therefore excluded from the analysis. According to the subject diaries, $99 \%$ of the prescribed capsules were taken, indicating good compliance.

Analysis of variance revealed no significant centerby-treatment interactions; accordingly, the results from the five centers were pooled (25).

The approximation of Friedewald et al. (21) LDL cholesterol $=($ total - HDL - VLDL $)$ cholesterol, where VLDL cholesterol concentration $=0.80 \times$ triglycerides concentration (in SI units) was checked in two centers (Cardiff and London) where VLDL cholesterol was measured directly. In the 19 subjects receiving active treatments, the average of the measured values/calculated values for VLDL cholesterol was 0.91 for the 95 placebo run-in samples, and 0.89 for the 135 samples drawn during the active treatment period $(P>0.05)$. Thus there was no evidence that the validity of the Friedewald approximation was affected by treatment with mevinolin. However, the individual values of VLDL cholesterol are subject to some uncertainty, as Friedewald et al. (21) point out. Because VLDL cholesterol is a small fraction of total cholesterol, the estimation of LDL cholesterol is not appre- ciably affected by any likely error in VLDL cholesterol determination.

Efficacy. Total serum cholesterol was $23-27 \%$ lower by the end of treatment in all the bid dosage groups (Fig. 1), (vs. placebo at day $29, P<0.01$ ), which was entirely attributable to a reduction in LDL cholesterol concentration of $35-45 \%$ (Figs. 1, 2); there was no significant change in HDL cholesterol, VLDL cholesterol, and triglycerides (Fig. 1). The reduction in LDL cholesterol was evident after $3 \mathrm{~d}$ of treatment and was essentially complete after $14 \mathrm{~d}$ (Fig. 3). LDL cholesterol tended to fall a little faster at the higher doses, but at the end of treatment, the effect of the top dose, $50 \mathrm{mg}$ bid, was only slightly and not significantly greater than that of the lowest dose, $6.25 \mathrm{mg}$ bid and there was no significant regression of effect on dose. (Figs. 1, 2). $25 \mathrm{mg}$ qd exerted an appreciable cholesterol-lowering effect (vs. placebo at $29 \mathrm{~d}, P$ $<0.05$ ), but less than that of 6.25 and $12.5 \mathrm{mg}$ bid (Figs. 1, 2), although this difference did not attain statistical significance. Apolipoprotein B concentrations (Fig. 4) were 25-34\% lower than base line in the bid dosage groups at day 29 (vs. placebo at day $29, P$ $<0.01$ ), and $20 \%$ lower than base line in the $25 \mathrm{mg}$ qd group (vs. placebo at day $29, P<0.05$ ).

The magnitude of the responses to treatment differed from center to center (Figs. 2, 4). This effect was statistically significant $(P<0.05$ by analysis of variance) for day 29 apolipoprotein B but not day 29 LDL cholesterol, and for LDL cholesterol at several of the earlier time points.

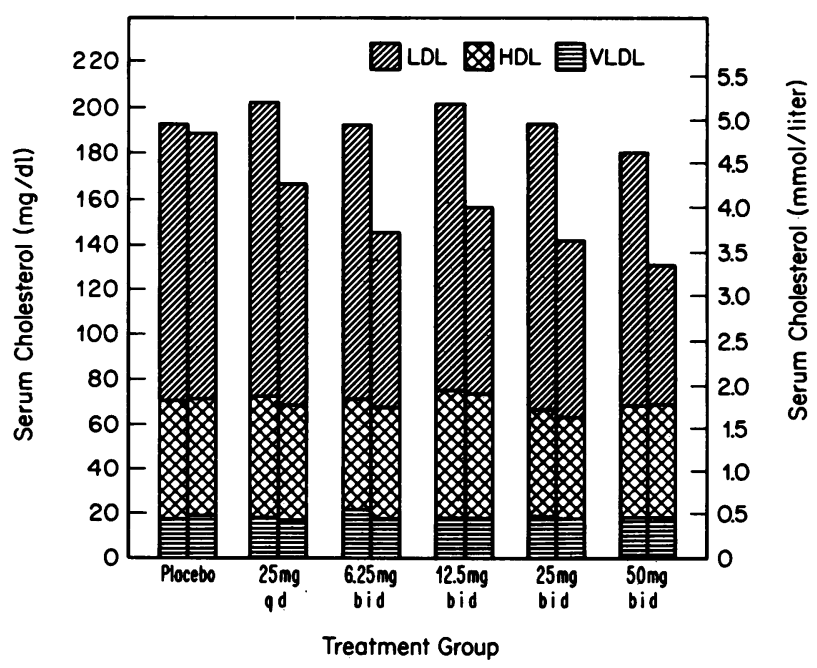

FIGURE 1 Effect of treatment on cholesterol in LDL, HDL, and VLDL. The bars on the left and right of each pair represent the base-line and posttreatment (day 29) mean values, respectively. Placebo, $n=10 ; 25 \mathrm{mg} \mathrm{qd}, n=10 ; 6.25 \mathrm{mg}$ bid, $n=9 ; 12.5 \mathrm{mg}$ bid, $n=8 ; 25 \mathrm{mg} \mathrm{bid,} n=10 ; 50 \mathrm{mg}$ bid, $n=8$. 


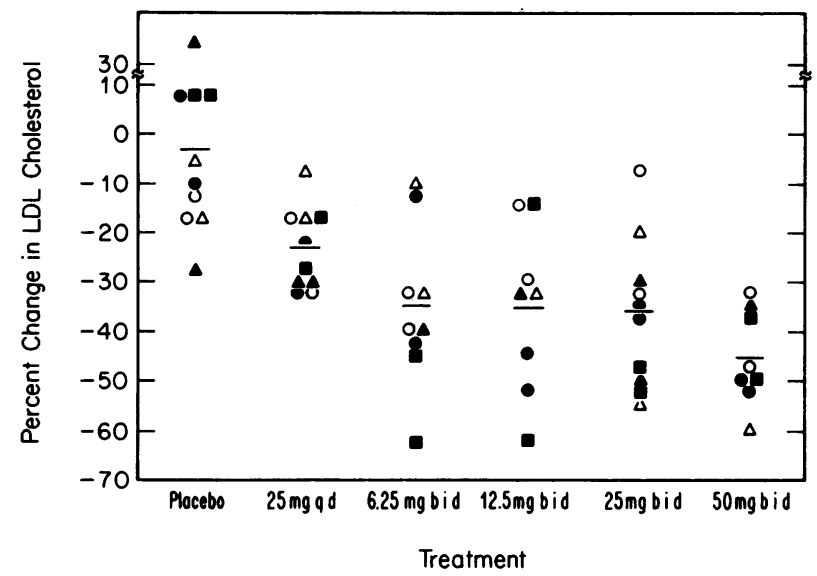

Figure 2 Effect of treatment on LDL cholesterol. Points represent percent change in LDL cholesterol for individual subjects. Means are indicated by horizontal lines. $\bullet$, Cardiff; $\mathrm{O}$, Graz; $\Delta$, London; $\Delta$, Norwich; $\boldsymbol{\square}$, Nottingham.

When the posttreatment results on all the bid doses were pooled, a positive correlation was observed between response, expressed as absolute fall in LDL cholesterol concentration at the end of treatment, and base line LDL cholesterol $(r=0.34, P=0.045)$. When response was expressed as percentage reduction, there was no correlation $(r=0.11, P=0.55)$.

Plasma cortisol and testosterone concentrations and urinary excretion of 17-hydroxysteroids and 17-ketosteroids were not significantly affected by mevinolin, although posttreatment values were generally slightly lower than base line in the active treatment groups (Table II).

Adverse events. There were no serious adverse events. One subject (AN 38, $12.5 \mathrm{mg}$ bid) was with-
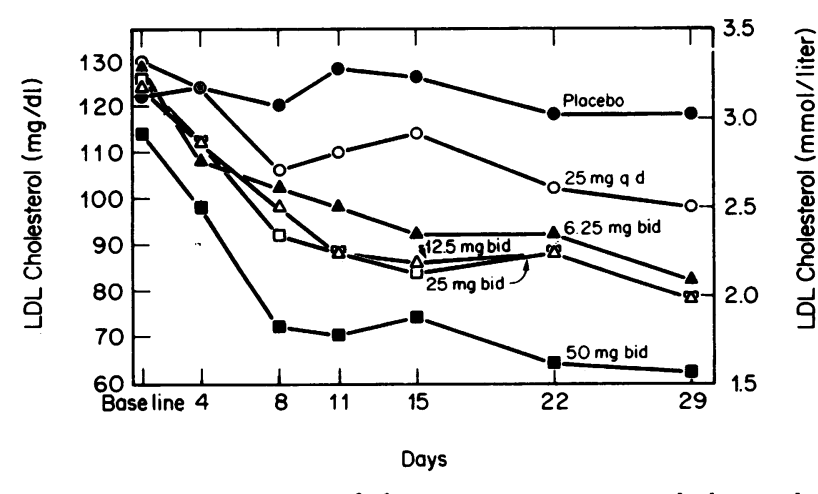

Figure 3 Time-course of changes in mean LDL cholesterol. -1 , placebo; $\mathrm{O}-\mathrm{O}$, mevinolin $25 \mathrm{mg} \mathrm{qd}$; $\Delta-\triangle, 6.25 \mathrm{mg}$ bid; $\Delta-\Delta, 12.5 \mathrm{mg}$ bid; $\square-\square, 25$ mg bid; $150 \mathrm{mg}$ bid. Placebo, $n=10 ; 25 \mathrm{mg} \mathrm{qd}$, $n=9 ; 6.25 \mathrm{mg}$ bid, $n=9 ; 12.5 \mathrm{mg}$ bid, $n=8 ; 25 \mathrm{mg}$ bid, $n=10 ; 50 \mathrm{mg}$ bid, $n=8$. (Subjects with missing data at any time point were excluded.) drawn from the study on day 21 because of severe diarrhea and abdominal pain; otherwise, all symptoms reported were mild or moderate in intensity, and no other subject had to have treatment discontinued. Adverse events are summarized in Table III. The transaminase values did not exceed $50 \mathrm{U} /$ liter; both the rashes were maculopapular and mild, and in one case had resolved by the end of the study.

\section{DISCUSSION}

As is expected in a multicenter study, the responses to treatment differed quantitively from center to center. The use of a balanced design and the absence of any significant center-by-treatment interactions permitted the pooling of the data without introduction of bias (25).

Lipid-lowering drugs have not often been investigated in normocholesterolemic volunteers, but the mean falls in serum cholesterol observed in this study are probably larger than can be obtained with any approved lipid-lowering agent, with the exception of cholestyramine and other bile acid sequestrants, which can produce a response of similar magnitude, but which (because of their bulk and taste) are poorly tolerated by many patients (26). Although caution is warranted when extrapolating results obtained in normal volunteers to the clinical situation, it is worth noting that a $35-45 \%$ reduction in LDL cholesterol, as observed in this study, would be sufficient for many hypercholesterolemic patients. It is also of interest that in dogs synergism between mevinolin and bile acid sequestrants has been reported (5).

The cholesterol-lowering effect of mevinolin was achieved by a reduction in the atherogenic LDL frac-

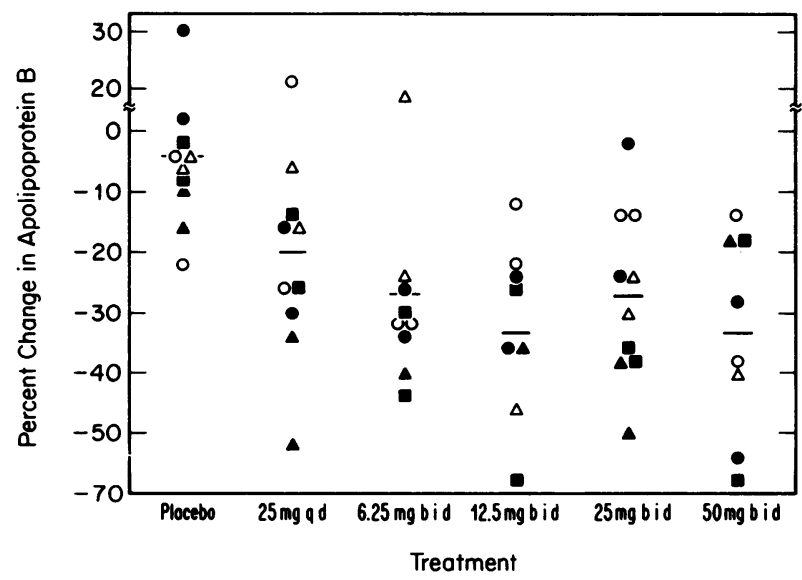

Figure 4 Effect of treatment on apolipoprotein B. Points represent percent change in apolipoprotein $B$ for individual subjects. Means are indicated by horizontal lines. Key as in Fig. 2. 
TABLE II

Effect of Mevinolin on Steroidogenesis

\begin{tabular}{|c|c|c|c|c|c|c|c|c|}
\hline \multirow[b]{2}{*}{ Treatment } & \multicolumn{2}{|c|}{ Plasma cortisol } & \multicolumn{2}{|c|}{ Plasma testosterone } & \multicolumn{2}{|c|}{ Urinary 17-ketosteroids } & \multicolumn{2}{|c|}{ Urinary 17-hydroxysteroids } \\
\hline & $\begin{array}{l}\text { Base } \\
\text { line }\end{array}$ & $\Delta \mathrm{SD}$ & $\begin{array}{l}\text { Base } \\
\text { line }\end{array}$ & $\Delta \mathrm{SD}$ & $\begin{array}{l}\text { Base } \\
\text { line }\end{array}$ & $\Delta \mathrm{SD}$ & $\begin{array}{l}\text { Base } \\
\text { line }\end{array}$ & $\Delta \mathrm{SD}$ \\
\hline & \multicolumn{2}{|c|}{ nmol/liter } & \multicolumn{2}{|c|}{ nmol/liter } & \multicolumn{2}{|c|}{$\mu \mathrm{mol} / 24 \mathrm{~h}$} & \multicolumn{2}{|c|}{$\mu \mathrm{mol} / 24 \mathrm{~h}$} \\
\hline Placebo & 601 & $50 \quad(99)$ & 26 & $0(8)$ & 44 & $11(19)$ & 28 & $2(14)$ \\
\hline $25 \mathrm{mg} \mathrm{qd}$ & 607 & $55(135)$ & 27 & $-1(8)$ & 46 & $1(14)$ & 36 & $-6(13)$ \\
\hline $6.25 \mathrm{mg} \mathrm{bid}$ & 648 & $-50(105)$ & 26 & $-3(3)$ & 41 & $1(16)$ & 29 & 3 (9) \\
\hline $12.5 \mathrm{mg} \mathrm{bid}$ & 508 & $-55(160)$ & 21 & $-3(6)$ & 41 & $-3(11)$ & 28 & $-1(12)$ \\
\hline 25 mg bid & 596 & $-41(135)$ & 27 & $-2(5)$ & 45 & $-3(14)$ & 36 & $-7 \quad(8)$ \\
\hline $50 \mathrm{mg}$ bid & 517 & $-55 \quad(99)$ & 24 & $-1(5)$ & 43 & $-2(20)$ & 29 & $-5(16)$ \\
\hline
\end{tabular}

Mean plasma cortisol and testosterone and 24-h urinary excretion of 17-ketosteroids and 17-hydroxysteroids; base line (day $8 \mathrm{R}$ ) means and posttreatment (day 29) mean changes from base line.

tion; the HDL fraction that is negatively correlated with ischemic heart disease $(2,27)$ was unaffected, as was the VLDL fraction. In this respect, mevinolin resembles cholestyramine but differs from clofibrate and nicotinic acid whose effects are exerted on both VLDL and LDL (26). Apolipoprotein B, which is the principal apoprotein of LDL and is claimed to correlate better with ischemic heart disease than LDL cholesterol (28), was also substantially lowered by mevinolin. Recently Kovanen et al. (5) have demonstrated that in dogs treatment with mevinolin leads to a reduction in LDL synthesis and an increase in the fractional catabolic rate for LDL; the latter could be attributed, at least in part, to an increase in the number of high affinity LDL receptor sites.

The relative ineffectiveness of once-daily administration ( $25 \mathrm{mg} \mathrm{qd}$ ) is consistent with preliminary results (unpublished data, Merck Sharp \& Dohme Div., Merck \& Co., Inc., West Point, PA.) showing that plasma levels fall to very low levels $24 \mathrm{~h}$ after a single dose of mevinolin in healthy volunteers. The lack of regression of effect on dose indicates that all the doses used in this study lie near the top of the dose-response curve in normocholesterolemic individuals when given bid. Insofar as one objective of the study was to define the dose-response curve, it is evident that we underestimated the potency of mevinolin.

The incidence, nature, and intensity of the adverse events noted in this study, not all of which were necessarily drug related, are considered quite acceptable relative to the potential therapeutic benefits, taking into account the fact that the top dose used was eight times the dose found to produce near-maximal pharmacological effects. The lack of a statistically significant effect of mevinolin on plasma testosterone and cortisol, and 17-hydroxysteroid and 17-ketosteroid excretion, indicates that steroidogenesis is probably not affected to any clinically important degree by mevinolin under normal conditions. However, there appeared to be a trend towards a reduction of these variables, and the possibility that a clinically significant effect might be observed when steroidogenesis is proceding at a high rate (e.g., during stress) cannot be ruled out.

None of the lipid-lowering agents currently in clinical use exert any major effect on the cholesterol synthesis pathway. Earlier attempts to reduce serum cholesterol by inhibiting its synthesis involved the use of drugs such as triparanol (MER-29) and AY-9944, which inhibit late steps in the cholesterol synthesis

TABLE III

Summary of Adverse Events

\begin{tabular}{cll}
\hline $\begin{array}{c}\text { Allocation } \\
\text { number }\end{array}$ & \multicolumn{1}{c}{ Dose } & \multicolumn{1}{c}{ Adverse effect } \\
\hline 31 & Placebo & Nausea/anorexia \\
41 & $6.25 \mathrm{mg}$ bid & Headache \\
60 & $6.25 \mathrm{mg}$ bid & Insomnia \\
38 & $12.5 \mathrm{mg}$ bid & Diarrhea/collicky pain \\
55 & $12.5 \mathrm{mg}$ bid & Elevation of SGPT \\
56 & $25 \mathrm{mg} \mathrm{qd}$ & Rash \\
11 & $25 \mathrm{mg}$ qd & Elevation of SGOT and SGPT \\
17 & $25 \mathrm{mg} \mathrm{bid}$ & Elevation of CPK \\
42 & $50 \mathrm{mg} \mathrm{bid}$ & Rash \\
29 & $50 \mathrm{mg} \mathrm{bid}$ & Nausea/malaise \\
52 & $50 \mathrm{mg}$ bid & Tiredness \\
57 & $50 \mathrm{mg}$ bid & Tiredness \\
32 & $50 \mathrm{mg}$ bid & Elevation of CPK \\
\hline
\end{tabular}

Adverse events; transient symptoms (i.e., those occuring on $<5 \mathrm{~d}$ ) are not tabulated. 
pathway $(29,30)$. Triparanol was introduced into clinical use but was withdrawn because of serious toxic effects, some of which may have been related to the build-up of the sterol intermediate desmosterol (31, 32). Inhibition of HMG-CoA reductase could not cause build-up of sterol intermediates.

ML-236B, a structurally related compound that is obtained from a differnt microorganism (33) and is a less potent inhibitor of HMG-CoA reductase (3), has recently been reported to be effective in the treatment of hypercholesterolemia $(34,35)$. In our short-term study, mevinolin was safe and generally well tolerated (particularly at the lower doses), and was very potent as a cholesterol-lowering agent, both in terms of response attained and on a milligram basis. If safety during long-term use can be demonstrated, inhibitors of HMG-CoA reductase may well provide an important advance in the treatment of hypercholesterolemia.

\section{ACKNOWLEDGMENTS}

The authors are indebted to Drs. A. Beubler, P. Cook, G. Maidment, and M. A. P. Meisinger for assistance with the performance of the study; to Dr. D. Harry, Mr. G. Howe, Ms. G. Kitchingman, Dr. W. Petek, and Ms. S. Williams for the lipid analyses; and to Dr. W. B. Abrams, Mr. A. W. Alberts, Drs. T. M. Hayes, K. H. Jones, and P. M. Lutterbeck for helpful advice and discussions.

\section{REFERENCES}

1. Gordon, T., and W. B. Kannel. 1972. Predisposition to atherosclerosis in the head, heart, and legs: the Framingham study. JAMA (J. Am. Med. Assoc.). 221: 661666 .

2. Grundy, S. M. 1977. Treatment of hypercholesterolemia. Am. J. Clin. Nutr. 30: 985-992.

3. Alberts, A. W., J. Chen, G. Kuron, V. Hunt, J. Huff, C. Hoffman, J. Rothrock, M. Lopez, H. Joshua, E. Harris, A. Patchett, R. Monaghan, S. Currie, E. Stapley, G. Albers-Schonberg, $\mathrm{O}$. Hensens, J. Hirshfield, K. Hoogsteen, J. Liesch, and J. Springer. 1980. Mevinolin: a highly potent competitive inhibitor of hydroxymethylglutarylcoenzyme A reductase and a cholesterol-lowering agent. Proc. Natl. Acad. Sci. U. S. A. 77: 3957-3961.

4. Rodwell, V. W., J. L. Nordstrom, and J. J. Mitschell 1976. Regulation of HMG-CoA reductase. Adv. Lipid Res. 14: 1-74.

5. Kovanen, P. T., D. W. Bilheimer, J. L. Goldstein, J. J. Jaramillo, and M. S. Brown. 1981. Regulatory role for hepatic low density lipoprotein receptors in vivo in the dog. Proc. Natl. Acad. Sci. U. S. A. 78: 1194-1198.

6. Tobert, J. A., G. Hitzenberger, W. R. Kukovetz, I. B. Holmes, and K. H. Jones. 1981. Rapid and substantial lowering of serum cholesterol by mevinolin (MK-803), an inhibitor of hydroxymethylglutaryl-coenzyme $\mathrm{A}$ reductase. Atherosclerosis. 41: 61-65.

7. Klose, S., H. Greif, and H. Hagen. 1975. Comparison of two newly developed enzymatic cholesterol-colortests on auto-analyzer-systems with other cholesterol tests. Clin. Chem. 21: 942.

8. Blomhoff, J. P. 1973. Serum cholesterol determination by gas-liquid chromatography. Clin. Chim. Acta. 43: 257-265.

9. Allain, C. C., L. S. Poon, C. S. G. Chan, W. Richmond, and P. C. Fu. 1974. Enzymatic determination of total serum cholesterol. Clin. Chem. 20: 470-475.

10. Warnick, G. R., and J. J. Albers. 1978. A comprehensive evaluation of the heparin-manganese precipitation procedure for estimating high density lipoprotein cholesterol. J. Lipid Res. 19: 65-76.

11. Burnstein, M., H. R. Scholnich, and R. Morfin. 1970. Rapid method for the isolation of lipoproteins from human serum by precipitation with polyanions. J. Lipid Res. 11: 583-595.

12. Bucolo, G., and H. David. 1973. Quantitative determination of serum triglycerides. Clin. Chem. 19: 476-482.

13. Eggstein, M. 1966. Eine Neue Bestimmung des Neutralfetts in Blutserum und Gewebe. II. Mitteilung der Zuverlassigkeit der Methode, anderer Neutralfettbestimmungen, Normalwerte fur Triglyceride. Klin. Wochenschr. 44: 267-273.

14. Cramp, D. G., and G. Robertson. 1966. Fluorimetric assay of triglyceride by a semiautomated method. Anal. Biochem. 25: 246-251.

15. Riad-Famy, D., G. F. Read, S. J. Gaskell, J. Dyas, and R. Hidawi. A simple direct radioimmunoassay for plasma cortisol featuring ${ }^{125} \mathrm{I}$ radioligand in a solid-phase separation technique. Clin. Chem. 25: 665-668.

16. Mattingly, D. 1962. A simple fluorimetric method for the estimation of free 11-hydroxy corticoids in human plasma. J. Clin. Pathol. 15: 374-379.

17. Dyas, J., G. F. Read, and D. Riad-Famy. 1979. A simple, robust assay for testosterone in male plasma using a ${ }^{125}$ radioligand in a solid-phase separation technique. Ann. Clin. Biochem. 16: 325-331.

18. Hillier, S. G., B. C. Brownsey, and E. H. D. Cameron. 1973. Some observations on the determination of testosterone in human plasma by radio immunoassay using antisera raised against testosterone $3 \mathrm{BSA}$ and testosterone 11 BSA. Steroids. 21: 735-754.

19. Few, J. D. 1961. A method for the analysis of urinary 17-hydroxy-corticosteroids. J. Endocrinol. 22: 31-46.

20. Gray, C. H., D. N. Baron, R. V. Brooks, and V. H. T. James. 1969. A critical appraisal of a method for estimating urinary 17 oxosteroids and total oxogenic steroids. Lancet. I: 124-127.

21. Friedewald, W. T., R. I. Levy, and D. S. Fredrickson. 1972. Estimation of the concentration of low-density lipoprotein cholesterol in plasma, without use of the preparative ultracentrifuge. Clin. Chem. 18: 499-502.

22. Ononogbu, I. C., and B. Lewis. 1979. Lipoprotein fractionation by a precipitation method. A simple quantitative procedure. Clin. Chim. Acta. 71: 397-402.

23. Sniderman, A., B. Teng, and M. Jerry. 1975. Determination of B-protein of low-density lipoprotein directly in plasma. J. Lipid Res. 16: 465-467.

24. Dunn, O. J. 1961. Multiple comparisons among means. J. Am. Stat. Assoc. 56: 52-64.

25. Kirk, R. E. 1968. Experimental design: procedures for the behavioral sciences. Brooks/Cole Publishing Company, Monterey, CA. 131-139, 171-178.

26. Levy, R. I. 1980. Drugs used in the treatment of hyperlipoproteinemias. In The Pharmacological Basis of Therapeutics. A. G. Gilman, L. S. Goodman, and A. Gilman, editors. Macmillan Publishing Co., Inc., New York, 834-847.

27. Miller, G. J., and N. E. Miller. 1975. Plasma high-den- 
sity-lipoprotein concentration and the development of ischaemic heart disease. Lancet. I: 16-19.

28. Sniderman, A., S. Shapiro, D. Marpole, B. Skinner, B. Teng, and P. O. Kwiterovich, Jr. 1980. Association of coronary atherosclerosis with hyperapobetalipoproteinemia [increased protein but normal cholesterol levels in human plasma low-density (B) lipoproteins]. Proc. Natl. Acad. Sci. U. S. A. 77: 604-608.

29. Avigan, J., D. Steinberg, H. E. Vroman, M. J. Thompson, and E. Mosettig. 1960. Studies of cholesterol biosynthesis: I. The identification of desmosterol in serum and tissues of animals and man treated with MER-29. J. Biol. Chem. 235: 3123-3126.

30. Dvornik, D., M. Kraml, J. Dubuc, M. Givner, and R. Gaudry. 1963. A novel mode of inhibition of cholesterol biosynthesis. J. Am. Chem. Soc. 85: 3309.

31. Achor, R. W. P., R. K. Winkelmann, and H. O. Perry. 1961. Cutaneous side effects from use of triparanol
(MER-29): preliminary data on ichthyosis and loss of hair. Proc. Staff Meet. Mayo Clin. 36: 217-228.

32. Laughlin, R. C., and T. F. Carey. 1962. Cataracts in patients treated with triparanol. JAMA (J. Am. Med. Assoc.). 181: 339-340.

33. Endo, A., Y. Tsujita, M. Kuroda, and K. Tanzawa. 1977. Inhibition of cholesterol synthesis in vivo by ML-236B. Competitive inhibitors of 3-hydroxy-3-methylglutaryl coenzyme A reductase. Eur. J. Biochem. 87: 313321.

34. Yamamoto, A., H. Sudo, and A. Endo. 1980. Therapeutic effects of ML-236B in primary hypercholesterolemia. Atherosclerosis. 35: 259-266.

35. Mabuchi, H., T. Haba, R. Tatami, S. Miyamoto, Y. Sakai, T. Wakasugi, A. Watanabe, J. Koizumi, and R. Takeda. 1981. Effects of an inhibitor of 3-hydroxy-3-methylglutaryl coenzyme A reductase on serum lipoproteins and ubiquinone-10 levels in patients with familial hypercholesterolemia. N. Engl. J. Med. 305: 478-482. 